\title{
A "PESCA" ESCOLAR COMO REPRESENTAÇÃO DE FRAUDE ACADÊMICA NO ENSINO MÉDIO INTEGRADO EM ELETROTÉCNICA
}

\author{
Maria do Socorro Ferreira dos Santos $^{1}$ \\ Rita de Cássia Costa \\ Recebido em: março/2020 \\ Publicado em: agosto/2020
}

\section{RESUMO}

O presente trabalho tem como objetivo o refletir sobre os motivos que levam os alunos da educação profissional a praticarem fraudes em avaliações acadêmicas. Essa prática, conhecida como "pesca" escolar impacta o processo ensino aprendizagem, bem como afeta o futuro profissional desses estudantes. Para tanto, fez-se a escolha da pesquisa-ação como percurso metodológico. Os resultados desta pesquisa apontam que os alunos não reconhecem a "pesca" como um ato fraudulento grave, já que eles acreditam que a cultura escolar justifica este ato, especificamente quando dentre os motivos mais frequentes estão os relacionados a não compreensão dos conteúdos ao longo do processo de aprendizagem.

Palavras-chave: ensino técnico integrado; pesquisa-ação; pesca escolar; fraude acadêmica.

\section{THE "CHEATING" AS A REPRESENTATION OF ACADEMIC FRAUD IN "SECONDARY TECHNICAL SCHOOL" IN ELECTROTECHNICAL}

This paper aims to reflect on the reasons that lead students of professional education to practice fraud in academic assessments. This practice, known as school "cheating" impacts the teachinglearning process, as well as affecting the professional future of these students. For that, actionresearch was chosen as a methodological path. The results of this research show that students do not recognize "cheating" as a serious fraudulent act, since they believe that school culture justifies this act, specifically when among the most frequente reasons are those related to the lack of understanding of the contentes in the learning process.

Key words: professional education; action research. to cheat; academic fraud.

\section{INTRODUÇÃO}

Importante entender que a "pesca escolar", também conhecida como "cola" ou "fila", é um instrumento utilizado por estudantes para atingirem sua promoção escolar, sem

\footnotetext{
${ }^{1}$ Professora do Instituto Federal de Alagoas/Campus Marechal Deodoro. E-mail: socorrofsantos@yahoo.com.br.

${ }^{2}$ Professora do Instituto Federal de Alagoas/Campus Maceió. E-mail: rcostamaceio@gmail.com
} 
necessariamente utilizar seu conhecimento próprio, ou seja, existir a promoção escolar sem ter acontecido aprendizagem por parte do aluno. Segundo Pimenta \& Pimenta (2016, p.955):

A fraude em avaliações é comumente chamada de cola, pesca, fila etc. termos usados no Brasil - e copianço, em Portugal. Observa-se que os termos usados nos dois países apresentam-se isentos de valoração, uma vez que estão focados no ato, sem alusão aos aspectos relacionais e às implicações do ato. Entendemos que a fraude acadêmica envolve aspectos relacionais que dizem respeito à relação que o estudante estabelece com o professor, com a instituição, em que estuda, e com as normas estabelecidas por ela. Com respeito às implicações do ato, ou seja, implicações da prática da fraude, dentre elas, destacamos a probabilidade da aprendizagem não ter ocorrido, pois, caso contrário, a cola seria desnecessária.

Nessa perspectiva, entende-se que, como a aprendizagem não ocorreu, o principal objetivo do trabalho do professor também não aconteceu, e a relação entre aluno e professor fica fragilizada, pois, sem saber que o aluno utilizou de meios fraudulentos em sua avaliação, o professor promoverá o referido aluno à próxima fase do processo de aprendizagem, já que a prova escrita, ao ser corrigida, apresenta um conteúdo compatível com o que foi ministrado em sala de aula. Logo, como não existe uma relação de confiança entre professor e aluno, essa relação fica prejudicada.

Além disso, a relação do aluno fraudador com seus demais colegas também merece especial atenção. O estudante que se utiliza da informação obtida com a fraude é o sujeito ativo, é aquele que tem a vantagem de obter nota para sua promoção. Nos casos em que outro indivíduo fornece a cola, será este considerado o agente passivo. Ambos, contudo, contribuem para a concretização da burla. (BUNN et al,1992 apud RAMOS, 2012, p.19)

Essa denominação de sujeito ativo e passivo nos leva a inferir que o aluno ativo prejudica a si mesmo por não obter o conhecimento necessário ao seu desenvolvimento, envolve seu colega na trama fraudulenta e fragiliza sua relação com o professor, já que a avaliação da aprendizagem não é feita verdadeiramente. Todos saem prejudicados desse processo.

Percebe-se que são várias as consequências desse ato, pois o processo ensinoaprendizagem também fica fragilizado, uma vez que o profissional que está em formação não adquiriu o conhecimento mínimo necessário para atuar no mundo do trabalho. E, em se tratando de profissionais da área técnica, essa prática torna-se ainda mais problemática, pois o baixo rendimento do aluno em sala de aula refletirá em seu exercício profissional no futuro. 
Pensando na formação desses profissionais, o projeto político pedagógico institucional (PPPI) do IFAL já aponta para a preocupação da formação ética de seus alunos, e em um dos seus objetivos estabelece: "construir uma organização didática para o Instituto Federal de Alagoas (IFAL) coerente com uma visão omnilateral que requer a formação de cidadãos éticos e atuantes socialmente tornou-se a grande preocupação dessa instituição". (IFAL, 2013, p.35)

Mas, apesar de afirmar ser coerente com a formação de cidadãos éticos, o PPPI do IFAL não explicita como deverá ser a sanção das práticas fraudulentas, deixando a cargo do professor coibir tal prática, cabendo a cada professor atribuir uma advertência, apreensão da prova ou alguma medida mais severa.

Analisando essa problemática, algumas perguntas emergem: será que a cultura escolar favorece essas atitudes fraudulentas? Que ações da cultura "organização escolar" estariam vinculadas a prática da pesca? Diante disso, Caixeiro (2011, p.23) afirma que

Os sistemas educativos acabam por fazer passar os valores que norteiam a sociedade e que esta pretende transmitir. Desta forma, podemos falar genericamente de uma cultura, que se cria e se preserva através da comunicação e cooperação entre os indivíduos na organização escolar.

Necessita-se, então, refletir sobre os valores que os atores praticantes da "pesca escolar" compartilham entre si e, especialmente, tentar compreender porque a organização escolar aceita de forma velada a cultura da "pesca escolar". A prática da "cola escolar" seria, então, uma cultura preservada no ambiente escolar, por meio da comunicação e da cooperação dos próprios alunos.

Segundo Silva (2006, p. 202), a escola tem uma cultura própria com atores que desenhariam essa cultura, quais sejam, as famílias, os professores, os gestores e os alunos. Além disso, apresentam-se elementos essenciais como os discursos e as linguagens construindo os modos de conversação e comunicação. Sobre essa questão, Caixeiro (2011, p.28) ainda acrescenta:

[...] a cultura escolar é uma realidade extremamente complexa, heterogénea e com clivagens, integrando várias subculturas, que conduz a uma autonomia dos indivíduos e uma panóplia de comportamentos numa perspectiva diferenciadora.

Poderia a prática da "pesca escolar" ser fruto dessas subculturas que formam o universo da organização escolar? E tornar-se uma prática que permanece muito presente no cotidiano escolar? É possível que sim. E para melhor entender esse contexto da organização escolar, 
Torres (2005, p. 448) afirma a existência de quatro eixos fundamentais que ajudam na compreensão dessa realidade:

i) das orientações culturais exógenas (cultura escolar), consubstanciadas nas "regras formais";

ii) das apropriações culturais endógenas (cultura organizacional escolar), processadas a partir do desenvolvimento de lógicas de acção (jogos sociais) plurais;

iii) da apreensão das relações entre os dentros e os foras da organização escolar, a partir do grau de permeabilização da escola ao meio/comunidade envolvente;

iv) em consequência, da natureza das manifestações culturais sedimentadas no tempo e conferidoras de uma identidade cultural distintiva.

Pelo exposto, percebe-se que existe a influência do que está fora do ambiente escolar, daquilo que já existe internamente sedimentado nesse ambiente e daquilo que é próprio do sujeito, tudo isso integrando para a formação da cultura praticada na escola, inclusive a cultura da "pesca escolar".

Mas, por outro lado, Teixeira (2000, p. 12) elenca alguns elementos constituidores da cultura organizacional da escola, entre eles tem-se:

i) os valores - que dizem respeito aos objetivos e representam a filosofia da organização; ii) as crenças e pressupostos - são conceitos que expressam o que é considerado verdade na organização, sendo inquestionáveis; iii) as normas - comportamentos sancionados que devem ser repassados aos novatos; iv) as comunicações - processo de interação social básico para criar, sustentar, transmitir e mudar a cultura; v) as histórias - narrativas baseadas em fatos que informam sobre a organização e reforçam sobre $o$ comportamento existente;

Tais elementos formam uma trama que envolve os atores que fazem parte do universo escolar. E, baseado em seus valores e crenças, eles praticam determinados atos que se internalizam e fazem parte da cultura escolar. Então, a prática da "pesca escolar” poderá ser analisada como resultado da cultura estabelecida entre os referidos atores? É bastante provável que esse comportamento, que burla as normas oficiais da escola, é repassado aos alunos novatos e, preservado, mantém-se oculto e muito enraizado no dia a dia dos alunos.

Importante pensar que, para Texeira (2000, p.14), essa cultura construída e aprendida, com seus aspectos negativos em alguns momentos, pode ser transformada, moldada. Essa pesquisadora afirma que, "tecida nas tramas das relações que se dão no interior das organizações, sua mudança não se faz por imposição, mas supõe adoção de novos valores, novas crenças". Isso implica em dizer que, para que as mudanças ocorram, as razões devem ser 
intrínsecas, ou seja, quando internamente as pessoas são levadas a avaliarem as consequências das suas ações.

A partir dessa discussão, pode-se perceber que a cultura da pesca internalizada entre os alunos poderá ser mudada na medida em que eles perceberem que tal prática afeta diretamente seu aprendizado e que isso interfere em sua vida profissional no futuro. Afinal, numa seleção a um estágio ou emprego, aquele candidato que aprendeu os conhecimentos de sua profissão logrará mais êxito, enquanto aquele que passou sua vida acadêmica se utilizando de práticas fraudulentas terá mais dificuldade em passar num concurso ou mesmo desempenhar sua função com maestria. Essa é a principal implicação no futuro do candidato que se utilizou da "pesca escolar".

Portanto, diante do exposto acima, o objetivo do presente artigo é apresentar uma discussão acerca dos motivos que levam os estudantes a "pescar" numa formação técnica profissionalizante.

\section{PERCURSO METODOLÓGICO}

Para o desenvolvimento deste trabalho, foi escolhida a pesquisa-ação, com abordagem qualitativa, realizada em múltiplas etapas que se inter-relacionam, caracterizada por seu caráter participativo, reflexivo, dialógico, dinâmico e cíclico de planejamento-ação-interpretação (THIOLLENT, TOLEDO, 2012; TOLEDO; GIATTI; e JACOBI, 2014).

$\checkmark$ A abordagem qualitativa desta pesquisa-ação foi composta pela primeira etapa, que consistiu da fase de diagnóstico por meio de questionários semiestruturados aplicados em turmas do $3^{\circ}$ ano e $4^{\circ}$ ano do Curso de nível médio integrado ao técnico de Eletrotécnica do Campus Maceió, em 2018;

$\checkmark$ Numa segunda fase, que consistiu no processo de intervenções, foram realizadas escolhas de práticas pedagógicas diferenciadas e motivadoras, para fins de comparação com outras práticas mais tradicionais já utilizadas no curso de Eletrotécnica, entre essas práticas motivadoras estão: Trabalho em grupo, Jogos Motivacionais, Resolução de problemas através de jogos, Avaliação Oral e montagem de circuitos elétricos, Desenvolvimento de Maquetes e momentos de confraternização, a fim de que o grupo estudado encontrasse as possíveis soluções ao problema apresentado; 
$\checkmark$ A terceira fase foi de aplicação do questionário pós-intervenções metodológicas em sala de aula;

$\checkmark$ E por fim, a quarta etapa foi a Descrição e Análise de dados;

Seguiu-se o ciclo estabelecido pela pesquisa-ação: a) diagnóstico; b) Definição de metas; c) Planejamento do processo; d) Avaliação do processo e dos resultados; e) Reflexão sobre os resultados do trabalho.

Dessa forma, após a reflexão, houve a replicação do questionário semiestruturado a ser utilizado na triangulação: ação, reflexão, ação.

A atividade como pesquisadora que trabalha com a pesquisa-ação colaborativa me faz compreender que, para mudar a teoria, a política e a cultura escolar, é necessário optar pelo desafio de co-produzir conhecimentos com os professores, aproximando o mundo da pesquisa ao da prática. (IBIAPINA, 2008, p. 106)

Nesta pesquisa-ação, o papel de pesquisadora e, ao mesmo tempo, participante da pesquisa, por meio da proposição das intervenções das atividades desenvolvidas pelos alunos, contribuiu para conhecer a percepção dos alunos sobre o fenômeno estudado (pesca escolar) e adquirir uma nova visão sobre essa problemática, o que modificou minhas práticas em sala de aula.

\section{RESULTADOS E DISCUSSÕES \\ PERFIL DOS PARTICIPANTES DA PESQUISA}

Participaram dessa pesquisa 36 alunos das turmas de $3^{\circ}$ e $4^{\circ}$ anos, em 2018 , do Curso Integrado de Eletrotécnica do Instituto Federal de Alagoas/Campus Maceió. Assim, serão considerados dois grupos de trabalho: Grupo A - alunos do $3^{\circ}$ ano e Grupo B - alunos do $4^{\circ}$ ano, sendo 18 alunos da turma do grupo A, na faixa etária de 16 anos a 19 anos, e 18 alunos da turma do grupo B (turma concluinte), com idade variando entre 17 e 20 anos.

O critério de escolha desses sujeitos de pesquisa foi a faixa etária, que fica entre a adolescência e o início da vida adulta.

Vale ressaltar que a autora da pesquisa também atuou como participante da referida pesquisa. 
A primeira fase da pesquisa, a diagnóstica, foi realizada por meio de questionários semiestruturados que obtiveram dados referentes à percepção dos alunos sobre o fenômeno estudado: a pesca escolar. Esses dados foram divididos nas seguintes categorias:

Categoria 1: O que é a pesca e o que leva o estudante a pescar?

Quadro 1 - comparação entre a percepção dos grupos sobre a definição de pesca.

\begin{tabular}{|c|c|}
\hline GRUPO A & GRUPO B \\
\hline Definição de pesca escolar & Definição de pesca escolar \\
\hline $\begin{array}{l}\text { Pescar é fraudar conhecimento; apropriação de ideias } \\
\text { que não lhe pertencem durante uma prova; pegar } \\
\text { indevidamente uma ajuda; ter vantagem; um jeito mais } \\
\text { fácil de tirar nota alta; pegar resposta de outro indivíduo } \\
\text { (não estando autorizado); uma forma de obter respostas } \\
\text { (por não ter estudado); pedir resposta da atividade a um } \\
\text { amigo; copiar a resposta do colega; ter acesso a uma } \\
\text { informação restrita no momento; consultar um assunto } \\
\text { ou atividade num momento que não lhe é permitido; } \\
\text { passar respostas da prova de alguém. }\end{array}$ & $\begin{array}{l}\text { Pesca é corrupção; desonestidade; meio } \\
\text { clandestino de obter respostas; responder de } \\
\text { maneira ilícita a um teste ou prova; é uma forma } \\
\text { de ajudar o colega que está necessitando de } \\
\text { ajuda; buscar outras alternativas quando não se } \\
\text { sabe; obter respostas sobre o que não sabe ou } \\
\text { lembra; usar a resposta de outras pessoas; é } \\
\text { transferir para um papel o que não aprendeu em } \\
\text { sala; buscar informação do que não se tem } \\
\text { conhecimento. }\end{array}$ \\
\hline
\end{tabular}

Fonte: as autoras da pesquisa (2018).

O quadro 1 ilustra que as respostas de ambos os grupos mostram inúmeras semelhanças e que os dois grupos têm consciência que pescar no ambiente escolar é uma prática de natureza ilícita, comparada a fraude, desonestidade e corrupção. "É comum no dia a dia se ouvir expressões como "desonestidade acadêmica", "má conduta acadêmica" e "trapaça acadêmica", referindo-se a transgressões no âmbito estudantil”. (GOUVEIA et all, 2018, pg. 29).

Além de saber a percepção dos alunos sobre a definição de pesca, o questionário também obteve as seguintes respostas sobre os motivos que levam os estudantes a pescarem.

O quadro 2 evidencia que ambos os grupos justificam o ato de pescar por não ter estudado o assunto anteriormente, por não ter compreendido o assunto devido ao método de ensino inadequado do professor, por questões emocionais, como nervosismo e por desejar ajudar o colega a obter êxito na promoção escolar. Além disso, a sobrecarga de muitos componentes curriculares da matriz curricular do curso técnico de eletrotécnica também influencia a decisão do estudante optar em pescar durante as avaliações acadêmicas.

Todas essas motivações fazem com que o aluno pense que não é antiético pescar em condições de que ele não foi o principal culpado pelo ato ilícito, já que existiu uma causa anterior movida pelo professor, que não ministrou uma aula eficiente, ou pela instituição escolar, que sobrecarrega o aluno com um número exaustivo de disciplinas no curso, ou ainda 
por fatores pessoais que o impossibilitam de estudar para a avaliação acadêmica. E, assim, o aluno acredita que é natural se utilizar de mecanismos fraudulentos para obter uma vantagem ilícita, pois ele não foi o culpado pela origem do problema.

Quadro 2 - comparação entre a percepção dos grupos sobre os motivos que levam os estudantes a pescar.

\begin{tabular}{|c|c|}
\hline GRUPO A & GRUPO B \\
\hline Motivos que levam à pesca escolar & Motivos que levam à pesca escolar \\
\hline $\begin{array}{l}\text { Não prestar atenção nas aulas; não ir para as aulas; } \\
\text { desespero para passar na matéria; disciplina } \\
\text { "inútil" para a vida acadêmica; preguiça de } \\
\text { estudar; falta de incentivo para estudar; ter dado } \\
\text { um "branco"; esquecer o assunto por conta do } \\
\text { nervosismo; Alzheimer; prova muito difícil; passar } \\
\text { a pesca quando tem um amigo necessitado; não } \\
\text { conseguir entender o assunto com os métodos de } \\
\text { ensino de certos professores; o IFAL se mostrou } \\
\text { mais estafante que o esperado, principalmente por } \\
\text { morar em interior (muitas vezes a sobrecarga de } \\
\text { matérias juntamente com a falta de tempo para } \\
\text { estudar me levou a pescar). }\end{array}$ & $\begin{array}{l}\text { Não gostar da matéria; falta de interesse; } \\
\text { dificuldade de aprendizagem; não lembrar das } \\
\text { fórmulas; não ter autoconfiança; influência dos } \\
\text { colegas; dificuldade de raciocínio devido a } \\
\text { doença; nível da avaliação está acima do nível da } \\
\text { aula; professores que não deram aulas muito } \\
\text { bem; por excesso de atividades (eu trabalho); } \\
\text { porque foi prova surpresa; por não ter entendido } \\
\text { o assunto e estar na reta final do ano letivo; } \\
\text { porque o nível da minha antiga escola e do IFAL } \\
\text { são muito diferentes. }\end{array}$ \\
\hline
\end{tabular}

Fonte: as autoras da pesquisa (2018).

Observando por esse lado (a percepção do aluno), algumas reflexões poderão ser consideradas pelo professor e pela instituição escolar. São estes últimos que decidem qual o melhor método de ensino, o tipo de avaliação que deverá ser feita para cada turma, quantas disciplinas deverão ser ofertadas anualmente.

Colocar o aluno no centro do processo ensino aprendizagem, levando em conta suas limitações, suas dificuldades de aprendizagem e suas oscilações emocionais (que são muito propensas na adolescência), poderá chegar à solução da problemática da pesca escolar, ou ao menos reduzir o problema.

Mais especificamente com relação ao professor, é necessário ressignificar sua prática em sala de aula, fazendo com que suas aulas chamem a atenção de seus alunos, despertem seu interesse, que suas avaliações sejam pautadas na responsabilidade da formação humanística, cidadã e profissional, conforme explicita Pimenta \& Pimenta (2016, p.954)

A delicada e complexa tarefa de avaliar envolve competência e responsabilidade em relação à formação humanística, cidadã e profissional dos estudantes. Entretanto, apesar de sua importante função no processo ensino-aprendizagem, a avaliação ainda é objeto de desconforto por parte de professores e estudantes, e de preocupação para pesquisadores. Isto se dá 
porque, apesar de servir para melhorar a aprendizagem quando informa sobre a adequação da metodologia (ensino), ela tem sido usada como instrumento de classificação e de discriminação. Cumpre ressaltar que ao melhorar o ensino e a aprendizagem, melhora a satisfação do professor com seu trabalho.

Assim, faz-se necessário um diálogo franco entre os diversos atores (aluno, professor e instituição escolar) para a redução da prática da pesca escolar, cada ator contribuindo para uma melhora na minimização do problema de "cola".

Além dos motivos que levam o estudante a pescar, o questionário também obteve respostas sobre quais eram as principais ferramentas utilizadas na pesca escolar. O quadro 3 resume estas respostas.

Quadro 3 - comparação entre a percepção dos grupos sobre as ferramentas utilizadas de pescar conhecidas pelos estudantes participantes da pesquisa.

\begin{tabular}{|c|c|}
\hline GRUPO A & GRUPO B \\
\hline $\begin{array}{l}\text { Formas de pescar conhecidas pelos estudantes } \\
\text { participantes desta pesquisa }\end{array}$ & $\begin{array}{l}\text { Formas de pescar conhecidas pelos } \\
\text { estudantes participantes desta pesquisa }\end{array}$ \\
\hline $\begin{array}{l}\text { *screver na borracha, na banca escolar, } \\
\text { no lápis, na tampa da calculadora, no } \\
\text { papel (papéis pequenos) e colar embaixo } \\
\text { da cadeira (antes da prova), ou colar no } \\
\text { fundo do copo; } \\
\text { Escrever no corpo (na mão, no pulso (e } \\
\text { esconder com casaco de manga longa), no } \\
\text { tornozelo, braço); } \\
\text { Escrever um código (para o professor } \\
\text { não desconfiar); } \\
\text { Olhar a prova do colega, ajuda mútua do } \\
\text { colega. }\end{array}$ & $\begin{array}{l}\text { * Uso do google no celular; } \\
\text { Escrever um resumo no papel (mínimos } \\
\text { textos); } \\
\text { * Papel no bolso; } \\
\text { *sconder o papel na tampa da lapiseira } \\
\text { ou no estojo; } \\
\text { * Colocar o papel escrito por baixo da } \\
\text { prova; } \\
\text { * Escrever na parede; } \\
\text { * } \text { para não esquecer; } \\
\text { * Assunto da prova escaneado e colado } \\
\text { na perna (calça); } \\
\text { Troca de provas durante a avaliação. }\end{array}$ \\
\hline
\end{tabular}

Fonte: as autoras da pesquisa (2018).

$\mathrm{O}$ quadro 3 demonstra que existe muita criatividade na maneira escolhida pelos estudantes na prática da pesca. Porém, sobressaem as formas que se utilizam de tecnologias, as que se utilizam de partes do corpo humano e as tradicionais, que vão desde a utilização de um simples pedaço de papel até a consulta ao colega ao lado.

O processo de globalização tende a facilitar a disseminação de ideologias consumistas. Esse processo inclui estratégias que afastam as diferenças que o ser humano possui em seu modo de agir, pensar e perceber o mundo à sua volta, padronizando a sociedade. ... a ideologia de consumo também dissemina uma cultura de resultados, a fraude acadêmica pode ser estimulada por este processo, pois se constata a existência de uma permissividade social e institucional em relação ao comportamento desviante. (RAMOS, 2012, p.12) 
A cultura de resultados citada anteriormente por Ramos (2012) explica o motivo dos estudantes se utilizarem das ferramentas tradicionais e tecnológicas para alcançarem bons resultados nas avaliações acadêmicas. É o reflexo de uma sociedade que valoriza os que são "bons", os que obtêm os melhores resultados, aqueles que conseguem as melhores notas.

E a pressão imposta pela sociedade força, de certa maneira, os alunos que desejam sairse bem, mas que não estão devidamente preparados, a enveredar para a pesca escolar. É a forma encontrada por eles para ficarem entre os melhores.

Mas o que as famílias dos alunos pensam a respeito da problemática da "fila"? O questionário da fase de diagnóstico aplicado também obteve respostas dos alunos para essa questão. Procurou identificar se os pais conversavam com seus filhos sobre pesca escolar. $\mathrm{O}$ quadro 4 resume essas respostas.

Categoria 2: A percepção da família sobre a pesca

Quadro 4: comparativo da percepção da família dos dois grupos discentes sobre a pesca.

\begin{tabular}{|l|ll|}
\hline \multicolumn{1}{|c|}{ GRUPO A } & & \multicolumn{1}{c|}{ GRUPO B } \\
\hline $\begin{array}{l}\text { Não concordam com tal ação, acham } \\
\text { errado e que eu deveria me dedicar mais } \\
\text { à escola e abdicar outras atividades para } \\
\text { usar o tempo nos estudos; }\end{array}$ & $\begin{array}{l}\text { Meus pais são contra a prática da "pesca } \\
\text { ou cola"; }\end{array}$ \\
$\begin{array}{l}\text { Eles falam: vá estudar porque senão não } \\
\text { aprende; }\end{array}$ & $\begin{array}{l}\text { Apenas querem que eu passe para o } \\
\text { próximo ano letivo; }\end{array}$ \\
$\begin{array}{l}\text { Acham algo injusto e desrespeitoso, } \\
\text { acham que é errado e desnecessário caso }\end{array}$ & $\begin{array}{l}\text { Abominam o ato e concordam com as } \\
\text { afirmações ditas a respeito que fazendo }\end{array}$ \\
$\begin{array}{l}\text { eu estudasse; } \\
\text { Eles falaram para eu estudar, para } \\
\text { aprender o assunto e ser honesto, evitar } \\
\text { "colar" porque é errado; }\end{array}$ & $\begin{array}{l}\text { issomenticará o aluno em algum } \\
\text { momento da vida; }\end{array}$ \\
$\begin{array}{l}\text { Eles disseram que tudo bem, só não pode } \\
\text { ser pego pescando. }\end{array}$ & $\begin{array}{l}\text { Nunca pesquem; } \\
\text { Minha mãe comentou que não é correto, } \\
\text { deu incentivo para estudar um pouco } \\
\end{array}$ \\
& $\begin{array}{l}\text { mais; } \\
\text { Quando eu era mais nova, falaram que } \\
\text { isso era algo errado. }\end{array}$ \\
\hline
\end{tabular}

Fonte: as autoras da pesquisa (2018).

O quadro 4 revela que apenas os pais de 01 (um) aluno concordam que seu filho pratique o ato de pescar, desde que o mesmo não seja pego pescando. Todos os outros são contra esse ato de pescar na escola. A semelhança das respostas obtidas nos dois grupos indica que a percepção da família concorre para que a pesca poderá refletir em prejuízo no futuro profissional do filho. 
ISSN: $2594-4827$

Ainda na fase de diagnóstico, o questionário aplicado obteve respostas sobre a cultura escolar que justifica a pesca, ilustrado no quadro 5.

Categoria 3: cultura escolar que justifica a pesca

Quadro 5: comparativo da percepção dos dois grupos discentes sobre a cultura escolar que justifica a pesca.

\begin{tabular}{|c|c|}
\hline GRUPO A & GRUPO B \\
\hline $\begin{array}{l}\text { O que mais influencia é o método e a } \\
\text { organização didática porque o aluno não } \\
\text { consegue compreender o assunto; } \\
\text { Maus professores, péssimo ambiente de } \\
\text { estudo, etc. O aluno não se sente } \\
\text { confortável com o ambiente, então não } \\
\text { estuda. Com toda certeza, quando a } \\
\text { instituição e os profissionais fazem com } \\
\text { que "o aprender" seja prazeroso facilite } \\
\text { esse processo, torna-o estimulante, } \\
\text { colaborativo e construtivo e não apenas } \\
\text { necessário e obrigatório; } \\
\text { Alguns professores passam muitos } \\
\text { assuntos de maneira muito rápida e passa } \\
\text { prova antes mesmo do aluno } \\
\text { compreender o assunto. } \\
\text { Porque aqui no IFAL as salas são um } \\
\text { pouco apertadas e isso facilita a pesca. } \\
\text { Não é desculpa. Não, porque o ensino é } \\
\text { bom e, os alunos ao invés de estudar } \\
\text { ficam no pátio, aí quando chega a hora } \\
\text { da prova, vai e pesca. Falta de interesse. }\end{array}$ & $\begin{array}{l}\text { Quantidade de matérias muito grande; } \\
\text { Às vezes, os professores não conseguem } \\
\text { fazer os alunos que tenham maiores } \\
\text { dificuldades a se interessarem pela } \\
\text { matéria; } \\
\text { Às vezes o assunto não é dado de forma } \\
\text { a tirar todas as dúvidas; } \\
\text { Às vezes o professor é muito rigoroso e } \\
\text { não passa os conteúdos de tal forma que } \\
\text { o aluno venha a aprender; } \\
\text { Às vezes os professores são muito } \\
\text { durões e não aceitam estar errados. E } \\
\text { dificultam a falta de compreensão dos } \\
\text { alunos. Ou o professor não sabe } \\
\text { explicar; } \\
\text { Algumas provas são muito exageradas; } \\
\text { O ato de "pescar ou colar" não depende } \\
\text { apenas do aluno (que não aprende), mas } \\
\text { da forma como ele é orientado na vida } \\
\text { acadêmica; }\end{array}$ \\
\hline
\end{tabular}

Fonte: as autoras da pesquisa (2018).

Analisando o quadro 5, é possível perceber que, apesar de terem consciência de que pescar não é uma atitude lícita, os estudantes participantes desta pesquisa entendem que são motivados a recorrer ao ato de pescar porque o ambiente escolar favorece à prática da pesca.

Em geral, o estudante não está motivado a aprender, pois só lhe é exigido que reproduza o conteúdo trabalhado em sala de aula. Ele não é motivado a usar sua criatividade para aplicar o conhecimento trabalhado em sala de aula a resolver problemas do seu entorno.

O adolescente do século XXI não aceita mais que o professor seja o "sabe tudo" que lhe repassa o conteúdo e quer participar ativamente do processo ensino aprendizagem. Cabe à escola do século XXI preparar esses jovens para enfrentar o "novo" mundo do trabalho: o mundo da quarta revolução industrial, caracterizada por inteligência artificial, realidade virtual, conectividade e interatividade. O profissional do futuro deverá ter habilidades multifuncionais, 
como, por exemplo, criatividade, saber transitar entre diversas áreas e não apenas a de sua especialidade. E a escola tem de preparar o referido profissional para enfrentar essa nova realidade, assim como o professor também deverá estar preparado para ajudar o aluno a adquirir as habilidades necessárias na quarta revolução industrial.

Ainda na fase de diagnóstico, foi solicitado ao aluno que fizesse algumas sugestões para mitigar a cultura da pesca escolar, resumidas no quadro 6.

Quadro 6: comparativo com sugestões dos dois grupos discentes sobre as ações que poderiam mitigar a cultura da pesca escolar.

\begin{tabular}{|c|c|}
\hline GRUPO A & GRUPO B \\
\hline SUGESTÕES & SUGESTÕES \\
\hline $\begin{array}{l}\text { Na minha opinião, todos os professores } \\
\text { deveriam pesquisar entre seus alunos, se } \\
\text { o método usado por ele para ensinar é de } \\
\text { fácil compreensão por parte dos alunos. } \\
\text { Caso não seja, deveriam estar abertos } \\
\text { para mudanças. } \\
\text { Investimento na preparação dos } \\
\text { professores que, muitas vezes, possuem } \\
\text { muito conhecimento, mas não sabem } \\
\text { transmiti-lo e não sabem lidar com o ser } \\
\text { humano, especialmente adolescentes, } \\
\text { não estão preocupados na formação do } \\
\text { ser, apenas na conta bancária "gorda" no } \\
\text { fim do mês. Melhorar a estrutura da } \\
\text { escola para realização de aulas práticas } \\
\text { decentes. Proporcionar que as aulas } \\
\text { sejam mais participativas e dinâmicas, o } \\
\text { que as tornam menos cansativas. } \\
\text { O ato da pesca ou cola se dá } \\
\text { principalmente pela necessidade que o } \\
\text { sistema impõe ao aluno de alcançar } \\
\text { médias aceitáveis para prosseguir o } \\
\text { avanço dos seus estudos, sem levar em } \\
\text { conta, no entanto, as condições do aluno } \\
\text { ao fazer a prova, ou mesmo o } \\
\text { desempenho dele durante as aulas. }\end{array}$ & $\begin{array}{l}\text { O assunto é polêmico. A sugestão é que } \\
\text { os professores tentem ajudar os alunos, } \\
\text { precisam saber mais sobre nossas } \\
\text { dificuldades e disponibilizar apostilas } \\
\text { de alguns assuntos; } \\
\text { "Quem não "cola" não sai da escola". É } \\
\text { meio impossível estudar para todas as } \\
\text { matérias e fazer todos os trabalhos. O } \\
\text { IFAL sobrecarrega demais o estudante; } \\
\text { Que não culpe apenas o aluno, mas } \\
\text { investigue toda parte de organização } \\
\text { didática e metodologia; } \\
\text { Ao meu ver é interessante, uma vez que } \\
\text { é algo comum, porém não é normal, } \\
\text { muito menos correto e, a pesquisa busca } \\
\text { identificar soluções para sanar o } \\
\text { problema; } \\
\text { Eu não gosto de pescar e admiro aquele } \\
\text { que nunca pescou. Muita gente, como } \\
\text { eu, prefere não estudar. Algo que no } \\
\text { futuro poderá pesar por não ter } \\
\text { aprendido o assunto. }\end{array}$ \\
\hline
\end{tabular}

Fonte: as autoras da pesquisa (2018).

O quadro 6 mostra que as sugestões apontadas pelos estudantes para que a realidade vivenciada na escola e não revelada abertamente sobre "pesca escolar" pode ser modificada a partir de investimentos em formação continuada dos professores, para que adquiram novos métodos de ensino; além disso, investimentos em infraestrutura da escola para que estes alunos tenham um ambiente propício a se apropriar do conhecimento; e, por fim, mas não menos importante, os estudantes reconheceram que o tema estudado - a pesca escolar - é um tema relevante e que deveria ser mais comentado entre os diversos atores da comunidade escolar, 
pois todos sabem que isso acontece, mas não é tratado de forma mais eficaz por parte da gestão, professores e alunos. Refletir sobre esse assunto se faz necessário.

\section{FASE DE INTERVENÇÃO}

A segunda etapa da pesquisa constituiu das intervenções em sala de aula, conforme as sugestões dos alunos na primeira etapa. Assim, foram realizadas algumas práticas que resgatassem o interesse dos referidos alunos pelos assuntos ministrados em sala de aula.

Dessa forma, foi escolhido o Trabalho em grupo para implementar a socialização e a interação entre os jovens. A capacidade de trabalhar em equipe é uma habilidade exigida pela indústria 4.0.

Jogos Motivacionais também foram utilizados para despertar o interesse em aprender o conteúdo trabalhado. Ou seja, deve-se trabalhar o lúdico para que os alunos gostem da disciplina e aprendam com prazer. A resolução de problemas através de jogos foi uma forma bastante agradável de executar os exercícios, pois os alunos não percebem o tempo passar.

A avaliação oral não favorece à pesca escolar, já que o aluno tem que responder ao professor se aprendeu o assunto ministrado e, caso ele não tenha aprendido, o professor detecta imediatamente o motivo da não aprendizagem. Assim, o professor pode rever seus métodos de ensino para eliminar as dificuldades de aprendizagem do aluno e facilitar-lhe o avanço para sua aprovação.

A montagem de circuitos elétricos e o desenvolvimento de maquetes são utilizados para relacionar a teoria estudada com a prática que o curso técnico requer. É uma forma de facilitar a aprendizagem e motivar os alunos a gostar de frequentar a sala de aula.

$\mathrm{E}$, finalmente, foram propiciados momentos de confraternização, a fim de que os grupos de alunos estudados se fortalecessem e se unissem, em prol de uma convivência mais amigável e fraterna. É importante salientar que esses momentos servem para desestressar o aluno, melhorar a relação aluno x professor e a relação aluno x aluno, pois estabelece uma relação de confiança. E, onde existe relação de confiança, a pesca escolar é desnecessária.

\section{ANÁLISE PÓS-INTERVENÇÃO}


Após as intervenções em sala de aula foi aplicado um novo questionário para descobrir a percepção dos alunos sobre as supramencionadas intervenções. É o início da terceira etapa da pesquisa.

E um dos questionamentos foi o seguinte:

Percebemos que o motivo de alguns estudantes praticarem a pesca escolar está relacionado a fatores como: organização didática, metodologia do professor e infraestrutura da escola. Na sua opinião, as intervenções feitas em sala de aula durante o semestre, como atividades práticas em laboratório e aula de campo, jogos motivacionais, construção de maquetes e vídeos, seminários e pesquisas na internet sobre temas de eletrotécnica melhoram o processo de apropriação de conhecimentos?

Em que foram constatadas, nas respostas dos grupos dessa pesquisa, inúmeras semelhanças, pois $96 \%$ dos estudantes do $3^{\circ}$ ano e $100 \%$ dos estudantes do $4^{\circ}$ ano concordam que novas metodologias de ensino, organização didática e boa infraestrutura da escola melhoram o processo de apropriação do conhecimento.

As justificativas apontadas pelos alunos do "grupo A" foram:

$\checkmark$ Ajuda no aprimoramento das disciplinas, visto que, por serem técnicas, atividades que visam mais as práticas do que as teorias são de fulcral importância no processo de aprendizagem do aluno;

$\checkmark$ Dessa forma, a vontade de conhecer realmente o que se está estudando aumenta;

$\checkmark$ Nem todos os alunos são bons em provas tradicionais; assim, com outros métodos, as notas podem melhorar;

$\checkmark$ Incentiva o aprendizado e desperta a vontade do aluno de estar presente;

$\checkmark$ Atrai mais a atenção e aumenta a vontade de estudar através da competitividade;

$\checkmark$ São experiências que ficam na mente;

$\checkmark$ Ajuda a ver o assunto de uma forma nova, principalmente as aulas práticas, que facilitam o entendimento;

$\checkmark$ A diversificação enriquece a aula e a torna menos pragmática;

$\checkmark$ Porque nos permite associar toda a teoria à parte prática; portanto, fica mais fácil entender o assunto;

$\checkmark$ Eles são ótimos para nos tirar da monotonia dos estudos e acaba dando aquele gás para gente; 
$\checkmark$ Nós interagimos mais e deixa de ser aquela aula chata;

$\checkmark$ Pelo fato que nos estimula de uma forma mais interativa, nos motivando a fazer algo que chame mais atenção das pessoas que irão assistir.

As justificativas apontadas pelos alunos do "grupo B" foram:

$\checkmark$ Pois é uma metodologia diferente de ensino, onde há uma maior interatividade entre aluno e professor, facilitando a aprendizagem;

$\checkmark$ Melhoram sim, pois de certa forma se torna mais fácil aprender, de maneira lúdica, sem a "pressão" de uma prova escrita comum;

$\checkmark$ Porque são artifícios que tiram a aula da formalidade;

$\checkmark$ Porque o assunto se torna mais interessante de ser trabalhado e sair da repetição;

$\checkmark$ Atividades mais práticas facilitam o aprendizado e, na maior parte das vezes, são mais estimulantes. A competição em jogos é ótima;

$\checkmark$ Porque se torna algo interessante, não é a mesma coisa monótona de sempre;

$\checkmark$ Com aulas mais práticas, é possível que os alunos se aprofundem nos temas e despertem mais curiosidade sobre os assuntos, além de interagir mais uns com os outros, compartilhando conhecimentos.

Ainda nessa fase da pesquisa, foi solicitado ao grupo A responder sobre o papel da escola, do professor e do aluno no processo da aprendizagem (ver quadro 7).

Quadro 7: Percepção do grupo A sobre o papel da escola, do professor e do aluno no processo da aprendizagem.

\begin{tabular}{|c|c|c|}
\hline ESCOLA & PROFESSOR & ALUNO \\
\hline $\begin{array}{c}\text { Tem que ter uma boa estrutura } \\
\text { para acolher o aluno; }\end{array}$ & $\begin{array}{c}\text { Tem que gostar do que faz, } \\
\text { para que o aluno absorva o } \\
\text { assunto com facilidade; }\end{array}$ & $\begin{array}{c}\text { Vendo o interesse do professor em } \\
\text { ensinar, o aluno fica com mais vontade } \\
\text { de aprender; }\end{array}$ \\
\hline $\begin{array}{c}\text { Além de alimentar o desejo } \\
\text { pelo conhecimento, deve } \\
\text { direcionar o aluno nesse } \\
\text { caminho. }\end{array}$ & $\begin{array}{c}\text { É educador, que guia como } \\
\text { uma bússola, mas não interfere } \\
\text { se o aluno quer ou não seguir, } \\
\text { isto é, dar a liberdade de } \\
\text { escolha ao aluno; }\end{array}$ & $\begin{array}{c}\text { Aluno é um explorador de } \\
\text { conhecimentos; }\end{array}$ \\
\hline $\begin{array}{c}\text { Fornece recursos necessários } \\
\text { para a absorção do } \\
\text { conhecimento; }\end{array}$ & $\begin{array}{c}\text { Faz uso dos recursos fornecidos } \\
\text { pela escola; }\end{array}$ & $\begin{array}{c}\text { Aproveita a oportunidade que tem de } \\
\text { aprender; }\end{array}$ \\
\hline $\begin{array}{c}\text { Preparar para o futuro, seja em } \\
\text { questão de emprego ou } \\
\text { convívio social; }\end{array}$ & $\begin{array}{c}\text { Conduzir esse processo da } \\
\text { melhor maneira; }\end{array}$ & $\begin{array}{c}\text { Esforçar-se para aprender o máximo } \\
\text { possível; }\end{array}$ \\
\hline
\end{tabular}




\begin{tabular}{|c|c|c|}
\hline $\begin{array}{c}\text { Fornece várias formas para o } \\
\text { aluno estar sempre na escola, } \\
\text { várias atividades, etc. }\end{array}$ & $\begin{array}{c}\text { Ensinar o assunto de forma que } \\
\text { todos aprendam; }\end{array}$ & $\begin{array}{c}\text { Vir para a escola tirar suas dúvidas com } \\
\text { quem sabe; }\end{array}$ \\
\hline $\begin{array}{c}\text { Dar suporte e um local } \\
\text { adequado para o estudo; }\end{array}$ & $\begin{array}{c}\text { Dar o assunto por métodos que } \\
\text { incentive os alunos a estar } \\
\text { sempre interessados no assunto; }\end{array}$ & Ser responsável e estudar direito; \\
\hline $\begin{array}{c}\text { Supervisionar e estar sempre } \\
\text { atenta às queixas quanto ao } \\
\text { método de aprendizado; }\end{array}$ & $\begin{array}{c}\text { Passar o conhecimento } \\
\text { superior; }\end{array}$ & Esforçar para entender e aprender; \\
\hline $\begin{array}{c}\text { É uma pré-aprendizagem para } \\
\text { o mundo (mercado). }\end{array}$ & $\begin{array}{c}\text { Transmitir o conteúdo de } \\
\text { maneira que facilite a } \\
\text { compreensão do aluno. }\end{array}$ & Aprender. \\
\hline
\end{tabular}

Fonte: as autoras da pesquisa (2018).

Diante das respostas deste grupo, fica clara a importância de que o papel da escola é fornecer meios para que o professor desenvolva seu trabalho e para que o aluno tenha um ambiente de aprendizagem propício ao seu desenvolvimento como técnico e cidadão. Já o papel do aluno é ter condições de se apropriar do conhecimento. Contudo, deverá existir diálogo entre os diversos atores da comunidade escolar para que todos desempenhem seu papel da melhor forma possível.

Sobre essa mesma questão os alunos do grupo B destacaram as seguintes questões (ver quadro 8).

Quadro 8: Percepção do grupo B sobre o papel da escola, do professor e do aluno no processo da aprendizagem.

\begin{tabular}{|c|c|c|}
\hline ESCOLA & PROFESSOR & ALUNO \\
\hline $\begin{array}{c}\text { Oferecer ao aluno a melhor } \\
\text { oportunidade para estudo; }\end{array}$ & $\begin{array}{c}\text { Instruir o aluno, instituir o } \\
\text { caminho ou o dever ao aluno; }\end{array}$ & $\begin{array}{c}\text { Tomar para si o conhecimento de que } \\
\text { deve e precisa, constantemente isso é } \\
\text { que servirá para toda sua vida; }\end{array}$ \\
\hline $\begin{array}{c}\text { Dar suporte para o aluno com } \\
\text { estrutura, materiais e } \\
\text { profissionais qualificados; }\end{array}$ & $\begin{array}{c}\text { Lecionar a matéria e incentivar } \\
\text { os alunos a ver o lado bom de } \\
\text { se entender a matéria, mesmo } \\
\text { que o aluno não veja } \\
\text { importância na matéria; }\end{array}$ & $\begin{array}{c}\text { Respeitar o esforço da escola e do } \\
\text { professor e estudar, não apenas para tirar } \\
\text { boas notas, mas para se tornar um ótimo } \\
\text { profissional; }\end{array}$ \\
\hline $\begin{array}{c}\text { Ofertar bom local para a } \\
\text { aprendizagem, além de } \\
\text { biblioteca, ambientes para } \\
\text { lazer, etc. Também deixar } \\
\text { psicólogos à disposição do } \\
\text { aluno; }\end{array}$ & $\begin{array}{c}\text { Ter um bom método de ensino } \\
\text { que esteja de acordo com os } \\
\text { alunos e suas necessidades, } \\
\text { alcançando o conhecimento em } \\
\text { todos os alunos; }\end{array}$ & $\begin{array}{c}\text { Esforçar-se para ir a todas as aulas, } \\
\text { fazendo as atividades; }\end{array}$ \\
\hline $\begin{array}{c}\text { Oferecer oportunidades; } \\
\text { Passar para os demais o } \\
\text { aprendizado que usará } \\
\text { (servirá) realmente. De } \\
\text { jeito didático e } \\
\text { empolgante. Tem professor } \\
\text { que ama o que faz e, tem }\end{array}$ & $\begin{array}{c}\text { Dever de absorver os conhecimentos e } \\
\text { agarrar as oportunidades; }\end{array}$ & \\
\hline
\end{tabular}


ISSN: $2594-4827$

\begin{tabular}{|c|c|c|}
\hline & $\begin{array}{l}\text { outros que fazem com má } \\
\text { vontade, de qualquer jeito; }\end{array}$ & \\
\hline $\begin{array}{l}\text { Fornece um ambiente onde } \\
\text { pessoas diferentes convivam } \\
\text { entre si e aprendam; }\end{array}$ & $\begin{array}{l}\text { Tem que haver primeiramente } \\
\text { uma conversa para o professor } \\
\text { conhecer o aluno, saber quais } \\
\text { as dificuldades e tentar ajudar } \\
\text { mudando o seu método; }\end{array}$ & $\begin{array}{l}\text { Dedicar-se ao aprendizado e } \\
\text { respeitar os professores; }\end{array}$ \\
\hline $\begin{array}{l}\text { A escola já cumpre bem o seu } \\
\text { papel, já alguns professores } \\
\text { precisam se importar mais com } \\
\text { seus alunos; }\end{array}$ & $\begin{array}{l}\text { Vários professores estão pouco } \\
\text { se lixando para os alunos, } \\
\text { sendo assim causam uma } \\
\text { desmotivação nos alunos, que } \\
\text { precisam se dedicar ainda mais } \\
\text { nos estudos; }\end{array}$ & $\begin{array}{l}\text { Chegar (falar com) no professor, no } \\
\text { monitor quando tiver dúvidas; }\end{array}$ \\
\hline $\begin{array}{l}\text { Todos devem trabalhar em } \\
\text { conjunto, a escola e o professor } \\
\text { devem auxiliar o aluno no } \\
\text { processo de aprendizagem e } \\
\text { não somente cobrar que o } \\
\text { aluno faça algo. }\end{array}$ & $\begin{array}{c}\text { Formar pessoas capacitadas } \\
\text { para os diversos setores da } \\
\text { sociedade. }\end{array}$ & $\begin{array}{l}\text { Deve sugar ao máximo todo } \\
\text { conhecimento, respeitando os seus } \\
\text { superiores e cumprindo seu papel de } \\
\text { estudante. }\end{array}$ \\
\hline
\end{tabular}

Fonte: as autoras da pesquisa (2018).

Analisando as respostas dos quadros 7 e 8, observa-se a grande semelhança na percepção de ambos os grupos. Todos concordam que tanto a escola, quanto professor e alunos têm seus papeis claramente definidos, mas falta diálogo entre esses atores para o devido cumprimento dos seus papéis.

Fica evidente que o cotidiano no ambiente escolar se desenvolve de forma em que, para os atores desempenharem seus papeis, uns precisam dos outros na construção de uma educação de qualidade.

Esse cotidiano foi estudado por Alves (2003, pg.63), que relaciona cultura e cotidiano escolar. A referida pesquisadora do cotidiano escolar afirma que "[...] existe uma corrente de pensamento que identifica esse cotidiano como uma "caixa preta". A utilização dessa metáfora torna "impossível" saber o que se passa, de fato, dentro da escola".

A visão do cotidiano escolar como uma "caixa preta" faz a comparação a um sistema, em que não importa o que se passa dentro da "caixa preta", mas a intervenção no sistema deve se dar sobre os planos de entrada (inputs). E a partir de uma realimentação com dados obtidos na finalização do processo anterior (feedback), possível através da avaliação dos indicativos fornecidos pelos resultados de saída (outputs). A aplicação das provas de final de ciclos e cursos nos fornece uma concretização desse modelo. (ALVES, 2003, pg. 63)

Nesse modelo tradicional, o papel do professor se resume a ministrar conteúdos em sala de aula; enquanto o papel do aluno é receber de forma passiva o conteúdo ministrado. E as 
provas no final de cada ciclo mostram se o aluno soube reproduzir o assunto trabalhado (resultado/saída do processo).

Mas a pergunta que se faz é: será que os alunos que cometem fraudes nas avaliações escolares conseguem resultados verdadeiros no processo de aprendizagem? Possivelmente, não, pois a avaliação não aconteceu verdadeiramente.

Por outro lado, contrapondo-se ao modelo tradicional, Alves (2003) ainda afirma que existe uma outra concepção sobre cotidiano escolar relacionada ao referencial teóricoepistemológico de Gramsci.

Para essa tendência, introduzir a dimensão cotidiana nos estudos de currículo era necessário para a compreensão da escola e das relações que mantinha com a realidade social mais ampla. Nessa tendência, era indispensável a participação ativa dos sujeitos. E está ligada também ao pensamento de Paulo Freire. (ALVES, 2003, pg.64)

Dessa forma, faz-se necessário observar que esta última tendência está mais próxima de uma metodologia inovadora, em que o aluno tem uma participação ativa, ficando no centro do processo de aprendizagem. E, por não ser passivo, sua aprendizagem torna-se mais significativa, sendo desnecessária a "pesca escolar". Também para o professor, com sua prática ressignificada, os resultados serão verdadeiros e mais próximos do idealizado. E, para a escola, tem-se o papel cumprido, o de ofertar uma educação de qualidade.

\section{CONSIDERAÇÕES FINAIS}

Os resultados desta pesquisa revelaram que todos os estudantes de ambos os grupos entendem o conceito de pesca, mas que para $96 \%$ dos alunos do grupo A e 100\% dos do grupo B, o ato de pescar no ambiente acadêmico é justificado por fatores como organização didática, metodologia adotada pelo professor e infraestrutura da escola.

Na percepção deles, acreditam que se não lhes foi fornecido um ambiente propício para sua aprendizagem, o ato de praticar a pesca não se torna tão grave, já que existiu uma justificativa para a pesca acontecer, e, dentre os motivos mais frequentes apresentados pelos estudantes, estão os relacionados ao fato de eles não terem tempo para estudar, pois o curso com muitas disciplinas (em torno de 15) sobrecarrega o aluno e lhe falta tempo para estudar; além do famoso "branco", que é o esquecimento durante as avaliações tradicionais (provas), já que o fator emocional influencia na concentração para realização das provas; e também por não 
terem compreendido o que lhes foi ensinado pelo professor, uma vez os métodos tradicionais são menos interessantes do que as metodologias ativas para os alunos; dentre outros motivos.

Já na categoria das respostas relacionadas à família, os alunos afirmam que seus pais condenam esta prática fraudulenta. Porém, uma resposta chamou atenção, por ter o consentimento de um dos pais, com a condição de que o filho não fosse "pego pescando", ou seja, fraudando no momento de sua avaliação escolar. É possível que, para esse pai, o importante é vencer a todo custo, não importando os meios para alcançar o sucesso.

$\mathrm{Na}$ fase de aplicação do questionário pós-intervenção foi constatado que a cultura escolar, a forma como a comunidade escolar enxerga a referida prática ilícita está naturalizada. Esta prática é tratada de forma velada pela comunidade escolar.

Espera-se que a comunidade escolar (alunos, professores, gestores e pais de alunos) debatam mais sobre esse tema e, em especial, os estudantes se sensibilizem para as graves consequências que esta prática fraudadora provoca na formação e no futuro do técnico em questão. E que, assim, os atores da comunidade escolar passem a coibir tal prática, adotando medidas inovadoras na forma de se apropriar o conhecimento - por parte do aluno. Que o professor repense sua prática em sala de aula, adotando alternativas às metodologias tradicionais de avaliação e que os pais incentivem mais seus filhos a não praticarem a pesca escolar, a fim de que esta fraude acadêmica seja eliminada da cultura escolar. E que surja, então, uma rede de apoio dentro dos muros da instituição escolar, estabelecendo condições para se evitar os motivos que levam o estudante a pescar.

\section{AGRADECIMENTOS}

Ao Instituto Federal de Alagoas, por possibilitar a execução desta pesquisa.

\section{REFERÊNCIAS BIBLIOGRÁFICAS}

ALVES, N. Cultura e cotidiano escolar. Revista Brasileira de Educação. $\mathrm{N}^{\circ} 23$. Maio/Jun/Jul/Ago, 2003.

CAIXEIRO, C. A. A cultura organizacional. Revista Alentejo Educação. N. ํ2, 2011.

IFAL, Instituto Federal de Alagoas. Projeto Político Pedagógico Institucional. Maceió:2013. 
IBIAPINA, I. M. L. de M. Pesquisa Colaborativa: investigação, formação e produção de conhecimentos. Brasília: Líber Livro Editora, 2008. 136p.

GOUVEIA, V. V. et al. Escala de autorrelato de trapaça-admissão: evidências de validade fatorial e precisão. Revista colombiana de psicologia, 27-40. Disponivel em: https://doi.org/10.15446/rcp.v27n1.46647.

PIMENTA, M. A. de A.; PIMENTA, S. de A. Fraude em avaliações no ensino superior do Brasil: aproximações com uma pesquisa de Portugal. Avaliação. Campinas; Sorocaba, SP, v. 21, n. 3, p. 953-974, nov. 2016.

RAMOS, F. S. Fraude acadêmica: uma análise ético-legislativa. Dissertação (mestrado). Uberaba, 2012.

SILVA, F. C. T. Cultura escolar: quadro conceitual e possibilidades de pesquisa. Educar, Curitiba, n. 28, p. 201-216, 2006. Editora UFPR.

TEXEIRA, L.H. G. Cultura organizacional da escola: uma perspectiva de análise e conhecimento da unidade escolar. RBPAE v.16, n.1, jan. /jun. 2000.

TOLEDO, R. F.; GIATTI, L. L.; JACOBI, P. R. A pesquisa-ação em estudos interdisciplinares: análise de critérios que só a prática pode revelar. Interface: comunicação, saúde e educação, 18(51):633-46, 2014.

TORRES, L. L. Cultura organizacional no contexto escolar: o regresso à escola como desafio na reconstrução de um modelo teórico. Ensaio: aval. pol. públ. Educ., Rio de Janeiro, v.13, n.49, p. 435-451, out./dez. 2005. 